\title{
Teachers' Emotional Expression in Interaction with Students of Different Ages
}

Simona Prosen ${ }^{* 1}$, Helena SMrtnik Vitulić ${ }^{2}$ And Olga PoljŠak ŠKraban ${ }^{3}$

$\propto$ Emotions are an integral part of "classroom life" and are experienced in teacher-student interactions quite often (Hosotani \& Imai-Matsumura, 2011). The present study focuses on teachers' emotions in classrooms. Its purpose is to establish which emotions are expressed by teachers in their interactions with students, the triggering situations of the two most frequent emotions, and their level of intensity and suitability. Teachers' emotions were observed by students of primary education during their practical experience work, in grades one to five. They used a scheme constructed for observing different aspects of emotions. The observations of 108 teachers in 93 primary schools from various Slovenian regions were gathered. The results show that primary school teachers express various pleasant and unpleasant emotions, with unpleasant emotions prevailing. The average frequency of teachers' emotion expression decreased from grade one to five. Anger was the most frequently expressed emotion $(N$ $=261)$, followed by joy $(N=151)$. Teachers' anger and joy were triggered in different situations: anger predominantly when students lacked discipline and joy predominantly in situations of students' academic achievement. The intensity of expressed anger and joy was moderate in all five grades, while the assessed suitability of these two emotions was high.

Keywords: Classroom, Emotion, Emotion expression, Observation, Primary school, Teacher's emotions

$1 \quad{ }^{\star}$ Corresponding author. Faculty of Education, University of Ljubljana simona.prosen@pef.uni-lj.si

2 Faculty of Education, University of Ljubljana

3 Faculty of Education, University of Ljubljana 


\section{Introduction}

\section{Emotion definition}

Emotions are complex psycho-physiological processes triggered in an individual as a response to a subjectively important event (Lazarus, 1991). They include specific sequences of physiological changes, cognitive processing, verbal and non-verbal expressions and behaviour or action tendencies (Oatley \& Jenkins, 1996). Emotions can be viewed from many different perspectives (Cole, Martin \& Dennis, 2004). Some authors (e.g., Bronfenbrenner, 1986, in Schutz, Cross, Hong \& Osborne, 2007; Hargreaves, 2000; Hochschild, 2008; Kelchtermans, 2005; Zembylas, 2005) emphasise the importance of social factors in their structuring, including influences ranging from the individual's microsystems (i.e., family, friends) to his or her macrosystems (cultural values, historical influences). However, some other authors (e.g., Izard, 1991; Lazarus, 1991) stress the role of the individual's internal characteristics in the emergence of emotions, such as temperament, expectations or personal resources.

Previous studies on emotions have focused on different aspects of the emotional process, such as emotion understanding, recognition, regulation or expression (e.g., Grazziano, Reavis, Keane \& Calkins, 2007; Gross \& Thompson, 2009; Harris, 1996; Siegel, 1999; Smrtnik Vitulić, 2009), including various dimensions of emotions: valence, intensity, duration or context suitability. The majority of authors (e.g., Fredrickson, 2004; Lamovec, 1991, Oatley \& Jenkins, 1996) have employed the "positive" and "negative" categorisation of emotions regarding their valence. When a subjectively important goal or expectation is accomplished or fulfilled, positive emotions are experienced (i.e., joy, pride); on the other hand, when an important goal is not accomplished or expectation not fulfilled, negative emotions appear (i.e., anger, sadness, fear). However, the valence of the emotions may not be confused with their usefulness: both positive and negative emotions may have an important adaptive function, since they enhance the individual's response to an important situation (e.g., Lazarus, 1991). In order to prevent possible confusion between the valence and usefulness of emotions, the pleasant-unpleasant categorisation was employed in the present study, instead of the positive-negative categorisation of emotions.

\section{Teachers' emotions in the classroom}

For teachers, it is not enough to have only academic knowledge and good teaching skills, it is also important to have emotional knowledge and skills 
for effective work with students. Emotions influence teacher-student interactions and shape the classroom atmosphere (Meyer \& Turner, 2007). Teachers' effective emotional skills may contribute to their good relationships with students, thus supporting students' adjustment to, and performance in, school, encouraging their learning process and motivation, as well as their memory and creativity (e.g., Frederickson, 2004, 2005; Lamovec, 1991). The cognitive "scaffolding" is held together with emotional bonds (Woods \& Jeffrey, 1996, in Hargreaves, 2000). Emotional bonds are emphasised more in elementary school, where a greater psychological and physical teacher-student closeness can be found (Hargreaves, 2000). On the other hand, the same author describes secondary school as characterised by greater psychological and physical distance, which may lead teachers to treat emotions in the classroom as intrusions.

Typically, emotions begin with the individual conscious or unconscious assessment of the personal meaning (appraisal) of some antecedent event (Lazarus, 1991). Thus, which emotions are experienced by teachers depends upon their appraisals of classroom situations. These appraisals are influenced by their individual goals and expectations, personal resources and previous experience (Sutton, 2007). Teachers' expectations regarding their own work are often unrealistically high, such as being prepared for and reacting effectively to every disciplinary issue, being able to motivate any student for schoolwork or being fully responsible for students' academic achievement (Gordon, 1997). These expectations often refer to their emotion experience and expression, as well and sometimes even including opposing convictions regarding which emotions should appear, when or how. Hosotani and Imai-Matsumura (2011) have identified two "ideal teacher" images appearing in teacher's expectations, namely the calm and the emotionally expressive teacher. In the first case, the teacher believes that any unpleasant emotion in the classroom is inappropriate, and thus refrains from its expression. The ideal of the calm teacher who excludes unpleasant emotions can lead to emotion suppression and be a source of subsequent unpleasant emotions, e.g., feeling guilty because of experiencing anger. On the other hand, the teacher who believes in the "emotionally expressive teacher ideal" always tries to express all emotions and uses them to evoke emotions in children. This ideal image can be a source of unpleasant emotions to teachers as well, since the ideal criteria cannot always be reached. "Ideal teacher" images are mostly a consequence of expectations of the social environment, including colleagues, students' parents, school management, school politics, cultural setting, etc. (e.g., Hosotani \& Imai-Matsumura, 2011; Schutz et al., 2007; Zembylas, 2004, 2005).

While working with students, teachers often experience and express different pleasant and unpleasant emotions, from joy to disappointment and anger 
(e.g., Chang, 2009; Cowie, 2011; Day and Leitch, 2001; Hargreaves, 2000; Hosotani \& Imai-Matsumura, 2011; Kelchtermans, 2005; Moè, Pazzaglia \& Ronconi, 2010; Shapiro, 2010; Zembylas, 2004). Several studies of teachers' emotions in the classroom (e.g., Hosotani \& Imai-Matsumura, 2011; Shapiro, 2010) have confirmed joy as the most frequently experienced pleasant emotion, whereas anger is the most frequent among the unpleasant emotions. Teachers' emotion experience and expression in the classroom are commonly triggered by students' learning process and achievement or by disciplinary problems. For example, Hosotani and Imai-Matsumura (2011) have reported that teachers felt angry when students were not following instructions, not motivated, not doing their best, etc., whereas teachers felt joy because of students' achievements and autonomy, during pleasant daily interactions with them, etc.

Teachers develop different strategies to regulate their emotions in the classroom, including changes in emotion valence, intensity or time course. Consequently, teachers' emotional expressions in front of children may be different from their authentic emotional experience. In Hosotani and ImaiMatsumura's research (2011), teachers mostly reported conscious control of the intensity of expressed anger. The second most frequent way of dealing with anger in teachers was its suppression. Nevertheless, some teachers admitted sometimes losing their temper and expressing their genuine anger towards students. In the same study, teachers reported expressing joy either authentically or as a tool to influence the student's behaviour (e.g., supporting the student's further endeavour), but also reported suppressing joy when they considered it may decrease the student's motivation for school work. Krevans and Gibbs (1996) critically discuss the practice whereby adults intentionally express emotions in order to condition children's behaviour, identifying it as problematic.

Studying teachers' emotions in the classroom represents an important issue in order to enhance the quality of their work with students. As mentioned above, emotions include different physiological and cognitive processes that are expressed in different ways. Some aspects of emotions can only be reached through self-reports (i.e., interviews, dairies, questionnaires), while others can be reached via their external observation. Studies applying introspective reports offer data on more subjective aspects of emotional experience and expression in the classroom (e.g., Hosotani \& Imai-Matsumura, 2011; Zembylas, 2004, 2005), while those applying the observational approach provided data on external indicators of emotional processes. The verbal and non-verbal expression of emotions is actually the most important guide for the external recognition of someone's emotions. In the classroom, the teacher's emotion expressions are a source of information about his or her emotions to the students, guiding 
their response to the teacher. This is the reason for choosing an observational approach to teachers' emotions in the natural setting (classroom) in the present study.

The goals of the present study are multifarious. We want to establish: (1) which emotions are expressed by primary school teachers in their interactions with students in the first five grades, with the two most frequent emotions being analysed in greater detail, comparing the results of the first five grades, (2) what situations trigger these two emotions, (3) what the level of their intensity is, and (4) how suitably these two emotions are expressed. The comparison of results gathered in the observation of teachers of different grades will be performed, because the characteristics of work with students of different ages vary in terms of the level of emotional exchange (e.g., Hargreaves, 2000; Papalia, Wendkos Olds \& Duskin Feldman, 2009).

\section{Methodology}

\section{Participants}

Teachers' emotions were observed by first year students of primary education during their practical experience work in the classroom. Each student did practical experience work at the primary school of her/his choice, mostly in their hometown. In this way 93 primary schools from various Slovenian regions were included in the study. The headmaster of the school then selected the classroom for student's practical work (first to fifth grade). Observations of 107 female teachers and one male teacher were gathered, in the first $(N=24)$, second $(N=21)$, third $(N=29)$, fourth $(N=20)$ and fifth grade $(N=14)$.

\section{Measure and procedure}

The data were collected by students of primary education of the Faculty of Education in Ljubljana. They participated in a special two-hour educational course on emotion recognition and description. During this course, they were also trained to use an observational scheme that included the type of emotion, a situation description, the emotion's verbal and non-verbal expression (including behaviour) and the responses of others participating in the interaction. The scheme also included the categories of intensity and suitability (how adequate a certain emotion expression is in a certain context) for each emotion, marked on a 5-point Likert scale (from 1 - very weak to 5 - very strong, and from 1 very unsuitable to 5 - very suitable, respectively). Students used the described 
scheme to observe and record teachers' emotions in the classroom. Each teacher's emotion was recorded when it occurred, in chronological order. If a certain emotion appeared more than once, it was recorded each time.

Students visited the selected classroom for five days during their practical experience work. During their fourth visit, they observed teachers' emotions for five hours in one school day. The teachers were informed about the goals of the students' practical experience work, including the observation of their work in general. After the observation of their emotion expressions, the teachers were fully informed about the study and consented to the use of the data.

The data collected by the students was checked by all three authors of the present article regarding the clarity of descriptions in all observed categories. For the purposes of the article, the following results will be presented: the type of emotion and - for the two most frequent emotions - the situations triggering them, their intensity and suitability. The statistical procedures for each particular section of the study are described simultaneously in the results' sections below.

\section{Results and discussion}

To explore primary teachers' emotions in the classroom, we analysed the type of emotions expressed by teachers in their interactions with students, the triggering situations of the two most frequent emotions, and their level of intensity and suitability. Certain attention was dedicated to a comparison of results regarding the grade that the teachers were working in, which ranged from the first to the fifth grade of primary school.

\section{Teachers' expressed emotions}

The results show that teachers express various emotions in the classroom, some very frequently and some less frequently. 
Table 1: The frequency of teachers' expressed emotions in different grades.

\begin{tabular}{|l|c|c|c|c|c|c|}
\hline & Grade 1 & Grade 2 & Grade 3 & Grade 4 & Grade 5 & Together \\
\hline Pleasant & 38 & 31 & 39 & 27 & 16 & 151 \\
\hline Joy & 8 & 8 & 2 & 4 & 3 & 25 \\
\hline Surprise & 3 & 3 & 3 & 1 & 2 & 12 \\
\hline Pride & 49 & 42 & 44 & 32 & 21 & 188 \\
\hline$\sum$ (pleasant emotions) & & & & & \\
\hline Unpleasant & 65 & 49 & 64 & 50 & 34 & 262 \\
\hline Anger & 12 & 8 & 18 & 8 & 6 & 52 \\
\hline Disappointment & 5 & 4 & 9 & 1 & 1 & 20 \\
\hline Fear & 2 & 5 & 2 & 1 & 1 & 11 \\
\hline Sadness & 0 & 0 & 4 & 1 & 0 & 5 \\
\hline Shame & 0 & 1 & 2 & 0 & 0 & 3 \\
\hline Guilt & 84 & 67 & 99 & 61 & 42 & 353 \\
\hline$\sum$ (unpleasant emotions) & 133 & 109 & 143 & 93 & 63 & 541 \\
\hline$\sum$ (all emotions) & 5.54 & 5.19 & 4.93 & 4.65 & 4.50 & 5.01 \\
\hline$M$ & & & & & \\
\hline
\end{tabular}

Note: $\quad N$ of all teachers $=108\left(N_{\text {first grade }}=24, N_{\text {second grade }}=21, N_{\text {third grade }}=29 ; N_{\text {fourth grade }}=20\right.$,

$\left.N_{\text {fifth grade }}=14\right) ; M=$ average frequency of all emotions

Studies of teachers' emotions in school (e.g., Chang, 2009; Hargreaves, 2000; Hosotani \& Imai-Matsumura, 2011; Kelchtermans, 2005; Shapiro, 2010) have reported that teachers experience and express pleasant and unpleasant emotions. Our study confirmed these results. There were nine different emotions recorded in the observation of teachers in grades one to five (Table 1): among pleasant emotions were joy, surprise and pride, while among unpleasant emotions were anger, disappointment, fear, sadness, shame and guilt.

In all grades, there were more unpleasant emotions detected (353 times) than pleasant emotions (188 times). The overall ratio between pleasant and unpleasant emotions was approximately 1:2. One of the important contemporary researchers in the field of emotions, Frederickson (2008), recommends a ratio of 3:1 in favour of pleasant emotions. For an individual to maintain an overall positive ratio between the emotions, one needs to compensate for unpleasant emotions with three times the amount of pleasant emotions, since unpleasant emotions influence the emotional balance more. Pleasant emotions increase the individual's physical, intellectual, motivational and social resources, which is why it is especially important to encourage the expression of pleasant 
emotions in the classroom. Pleasant emotions in teacher-student interactions may contribute to a pleasant atmosphere in the classroom, supporting students' competence and autonomy (Meyer \& Turner, 2007). However, our results, showing approximately twice as many unpleasant emotions as pleasant emotions, are not in line with Frederickson's recommendation. The question is how such a predominance of unpleasant emotions reflects in teachers' work and in classroom atmosphere. Teachers' expression of pleasant emotions should be encouraged (Sutton, 2007), but it is important to consider their authenticity and sensitive placement.

Of all of the detected emotions, anger was the most frequently reported emotion ( 262 times), followed by joy (151 times). These results can be linked to the findings of Hosotani and Imai-Matsumura (2011) and Shapiro (2010), according to which anger was the most frequent unpleasant emotion of teachers in the classroom, while joy was the most frequent pleasant emotion. This is why these two emotions will be analysed in greater detail in the following sections of the present article.

As mentioned above, besides joy and anger, other pleasant and unpleasant emotions were expressed by teachers in the present study. The frequencies and the most common triggering situations of each emotion will be stated. Among pleasant emotions, besides joy, there were surprise $(N=25)$, when students did something pleasant or achieved unexpectedly, and pride ( $N$ =12), when students' academic performance was excellent. Among unpleasant emotions, besides anger, teachers also expressed disappointment $(N=52)$ or sadness $(N=11)$, both when students did not fulfil teachers' expectations, and fear $(N=20)$ when students were in danger. Shame $(N=5)$ and guilt $(N=3)$ also appeared, triggered by teachers' perceived incompetency, but only in some grades.

There was a trend of slight decrease in the average frequency of teachers' expressed emotions from grade one to grade five, as shown in the last row of the Table 1. Hargreaves (2000) found that teachers' emotional expressiveness decreased with their students' age when comparing primary and secondary school teachers. Teachers in lower grades established closer emotional bonds with their students as a foundation for teaching and learning (Hargreaves, 2000). A similar argument may be applied to the results of the present study, where teachers' emotional expressiveness decreased from grade one to grade five. 


\section{Frequencies and triggering situations of joy and anger in different grades}

As already mentioned, joy and anger were the two most frequent emotions that teachers expressed in the classroom. Lazarus (1991) defines joy as a pleasant emotion that people experience when they conclude they have accomplished a subjectively important goal. Anger is an unpleasant emotion that is generated by a judgment that someone could and should have done otherwise (Weiner, 2007).

Further analyses of these two emotions were performed, including the triggering situations of joy and anger and the average frequency of teachers' expressions of these two emotions from grade one to grade five (Table 2). Students' descriptions of the situations that triggered teachers' emotions were reviewed by all three authors of the study and organised into six response categories for joy and another six response categories for anger. Each description was then placed into one of these categories.

Table 2: The frequencies and triggering situations of joy and anger in different grades.

\begin{tabular}{|c|c|c|c|c|c|c|}
\hline & Grade 1 & Grade 2 & Grade 3 & Grade 4 & Grade 5 & Together \\
\hline \multicolumn{7}{|l|}{ Joy } \\
\hline Achievement & 16 & 13 & 16 & 10 & 3 & 58 \\
\hline Funny events & 7 & 8 & 4 & 10 & 6 & 35 \\
\hline Relaxation & 5 & 3 & 10 & 4 & 3 & 24 \\
\hline Following instructions & 4 & 6 & 4 & 3 & 2 & 19 \\
\hline Novelty & 3 & 0 & 4 & 0 & 2 & 9 \\
\hline Others & 3 & 1 & 1 & 0 & 0 & 5 \\
\hline$\sum$ (joy) & 38 & 31 & 39 & 27 & 16 & 151 \\
\hline$M$ (average frequency of joy) & 1.58 & 1.48 & 1.35 & 1.35 & 1.14 & 1.40 \\
\hline \multicolumn{7}{|l|}{ Anger } \\
\hline Lack of discipline & 28 & 26 & 19 & 19 & 12 & 104 \\
\hline Not following instructions & 15 & 12 & 17 & 15 & 10 & 69 \\
\hline Inattention & 14 & 8 & 21 & 8 & 9 & 60 \\
\hline Underachievement & 2 & 1 & 2 & 6 & 2 & 13 \\
\hline Danger & 5 & 0 & 2 & 2 & 1 & 10 \\
\hline Others & 1 & 1 & 3 & 0 & 0 & 5 \\
\hline$\sum$ (anger) & 65 & 48 & 64 & 50 & 34 & 261 \\
\hline$M$ (average frequency of anger) & 2.71 & 2.29 & 2.21 & 2.50 & 2.43 & 2.42 \\
\hline
\end{tabular}

Note: $N$ of all teachers $=108\left(N_{\text {first grade }}=24, N_{\text {second grade }}=21, N_{\text {third grade }}=29 ; N_{\text {fourth grade }}=20, N_{\text {fifth grade }}=14\right)$ 
In other studies of teachers' emotions in the classroom, authors (e.g., Chang, 2009; Hosotani \& Imai-Matsumura, 2011; Shapiro, 2010) have reported that joy and anger were commonly triggered by students' learning process and achievement or by disciplinary issues. For example, Hosotani and Imai-Matsumura (2011) have reported that teachers felt joy because of students' achievements and autonomy or during pleasant daily interactions with them, and that teachers felt anger when students were not following instructions, not motivated or not doing their best.

The results in the present study show that teachers' joy and anger were aroused in various situations. In the case of joy, triggering situations included: students' achievement $(N=58$, i.e., a student calculates correctly; a student does her homework), funny events ( $N=35$; i.e., a student tells a joke), relaxation $(N=$ 24; i.e., a student celebrates his birthday; students play), following instructions ( $N=19$; i.e., students tidy the classroom; a student brings the required equipment), novelty ( $N=9$; i.e., a student brings an interesting toy) and a few other situations ( $N=5$; i.e., a vet's visit to the classroom).

The average frequency of teachers' expressions of joy decreased from grade one to grade five. Such a trend can be explained similarly to the trend of decreasing overall emotion expression mentioned above in the present study and potentially explained by Hargreaves (2000): working with younger students is characterised by the teacher's greater psychological and physical closeness to them, resulting in his or her more frequent emotion experience and expression. Another reason for the decreasing trend of joy expression from grade one to grade five in the current study may be connected to the issue of students' achievement, since this was the most frequent triggering situation of joy. Why did teachers express more joy at younger students' achievements than at the achievements of older students? Is it because teachers believe that expressing joy at students' achievements is a greater motivational factor for academic performance in younger than in older students? It may also be that teachers' expectations regarding students' achievements grow with students' age, allowing less room for joy.

In our study, in grades one to five the majority of teachers expressed joy once during the observation (modus $=1$ for each grade). For different grades, teachers' expression of joy ranged from zero to seven. This range indicates that joy expression varied among the teachers. The question is how the frequency of joy expression contributes to teacher-student interactions in the classroom, especially if there is no joy expressed by a teacher or when the joy is expressed abundantly.

Teachers expressed anger when students lacked discipline $(N=104$; i.e., 
students are fighting with each other; a student pinches her neighbour; students are restless), were not following instructions $(N=69$; i.e., a student does the exercise incorrectly because she did not follow the teacher's directions), were inattentive ( $N=60$; i.e., a student loses his belongings), did not perform well academically - underachieved ( $N=13$; i.e., a student does not know the answer when asked), were in danger ( $N=10$; i.e., a student pushes someone, students jump from a very high object) and in a few other situations ( $N=5$; i.e., a student rebels).

The average frequency of teachers' expressions of anger decreased from grade one to grade three $\left(M_{\text {first grade }}=2.71, M_{\text {second grade }}=2.29, M_{\text {third grade }}=2.21\right)$ but increased again in grades four and five $\left(M_{\text {fourth grade }}=2.50, M_{\text {fifth grade }}=2.43\right)$. This may stem from various sources. The decrease in anger expression from grade one to grade three may be explained by the fact that a lack of discipline was the most frequent situation triggering teachers' anger. Perhaps such situations decrease, as with age children gradually gain social competencies due to increasing self-regulatory capacities and learn how to respond to disciplinary demands by generating strategies for negotiation and handling social conflicts (e.g., Papalia et al., 2009).

But why did anger appear again more frequently in the fourth and fifth grades? It may be that this is facilitated by school subjects becoming increasingly difficult in higher grades (Woolfolk, 2002), and by the change from descriptive to numerical assessment of students in the fourth grade in Slovenia. In line with this, teachers may feel more responsible for students' achievement and are therefore more often angry if students do not follow their guidance regarding school work. This may be seen from the quite frequently detected anger triggering situations in our study, such as "not following instructions" and "inattention". Shapiro (2010) assumes that teachers' sense of powerlessness in accomplishing their educational goal may also contribute to their anger.

Similarly as noted previously for joy, anger expression also varied among teachers. In different grades, the majority of teachers expressed anger once or twice during the observation (modus $=1$ for first and fourth grades; modus $=2$ for the second, third and fifth grades), with teachers' expression of anger ranging from zero to ten in different grades. The lowest frequencies of anger expression may indicate the teacher's satisfaction with the students' behaviour, while the highest frequencies may have the opposite meaning. Perhaps rare or frequent anger expression is also connected to teachers' "ideal teacher" images (Hosotani \& Imai-Matsumura, 2011). Teachers who see any unpleasant emotion (i.e., anger) in the classroom as inappropriate refrain from its expression. On the other hand, teachers with an "emotionally expressive" ideal always try to show all of their emotions, using them to evoke emotions in students. 


\section{The intensity and suitability of joy and anger in different grades}

The two most frequently expressed emotions in our study, joy and anger, were also compared regarding their level of intensity and suitability.

Intensity represents a dimension of emotions describing the power of their expression. In our study, it was marked on a five-point Likert scale, ranging from very weak (1) to very strong (5) expression. Suitability is another dimension according to which emotions can be explored. It concerns the notion of how adequate a certain emotion expression is in the specific context in which it appears. An example of a highly inadequate emotion expression would be the teacher shouting at the student when he or she unintentionally dropped a pencil. In our study, suitability was appraised from very unsuitable (1) to a very suitable (5).

Table 3: Descriptive statistics of the intensity of teachers' joy and anger in different grades and ANOVA results.

\begin{tabular}{|l|c|c|c|c|c|c|c|c|c|c|c|c|c|}
\hline & \multicolumn{2}{|c|}{ Grade 1 } & \multicolumn{2}{c|}{ Grade 2 } & \multicolumn{2}{c|}{ Grade 3 } & \multicolumn{2}{c|}{ Grade 4 } & \multicolumn{2}{c|}{ Grade 5 } & \multicolumn{3}{|c|}{ ANOVA } \\
\hline & $M$ & $S D$ & $M$ & $S D$ & $M$ & $S D$ & $M$ & $S D$ & $M$ & $S D$ & $d f$ & $F$ & $p$ \\
Joy & 3.28 & 1.09 & 3.97 & 1.02 & 3.51 & 1.14 & 3.37 & .88 & 3.50 & .89 & 4 & 2.06 & .09 \\
Anger & 3.25 & 1.19 & 3.47 & 1.14 & 3.33 & 1.02 & 3.16 & 1.04 & 3.21 & .91 & 4 & .62 & .65 \\
\hline
\end{tabular}

In all grades, the intensity of joy and anger expressions was above the middle on the 5-point scale used for its assessment. The intensity of joy was slightly higher than the intensity of anger. For both emotions, the results of one-way analysis of variance regarding the intensity of teachers' joy and anger expressions in the classroom revealed no significant differences in this dimension throughout the first to the fifth grade. These results suggest that teachers' joy and anger expression in all grades were moderate.

Table 4: Descriptive statistics of the suitability of teachers' joy and anger in different grades and ANOVA results.

\begin{tabular}{|l|c|c|c|c|c|c|c|c|c|c|c|c|c|}
\hline & \multicolumn{2}{|c|}{ Grade 1 } & \multicolumn{2}{c|}{ Grade 2 } & \multicolumn{2}{c|}{ Grade 3 } & \multicolumn{2}{c|}{ Grade 4 } & \multicolumn{2}{c|}{ Grade 5 } & \multicolumn{3}{|c|}{ ANOVA } \\
\hline & $M$ & $S D$ & $M$ & $S D$ & $M$ & $S D$ & $M$ & $S D$ & $M$ & $S D$ & $d f$ & $F$ & $p$ \\
Joy & 4.53 & .86 & 4.71 & .63 & 4.49 & .82 & 4.63 & .57 & 4.31 & .95 & 4 & .89 & .47 \\
Anger & 3.91 & 1.18 & 3.82 & 1.30 & 3.95 & .98 & 3.94 & 1.06 & 3.76 & 1.10 & 4 & .24 & .92 \\
\hline
\end{tabular}

In all grades, the suitability of joy and anger expressions was quite high (around 4 on the 5-point scale). On average, the suitability of joy was close to its 
highest level and the suitability of anger was only slightly lower. For both emotions, the results of ANOVA regarding the suitability of teachers' joy and anger expressions in the classroom again did not reveal any significant differences in this dimension throughout the first to the fifth grade. In line with these results, it can be concluded that students assessed teachers' joy and anger expression in all grades as highly suitable.

Notwithstanding, a number of questions are facilitated by the contents of the dimension of suitability itself. Suitability is a complex dimension, since it simultaneously includes both the evaluation of the emotion expression and the context. Furthermore, suitability may be closely linked to the expectations that teachers have regarding themselves, which are affected by their "ideal teacher" images. Moreover, in the present study, the observers were future teachers and their "ideal teacher" images may have contributed to their assessment of teachers' emotion expression suitability as well. The high values of suitability rates are perhaps indicative of a concordance between the aforementioned ideal images of the teachers in the classroom and the "future" teaching professionals. The suitability dimension could also be influenced by the social and cultural expectations and rules on which, when and how emotions should occur.

\section{Conclusions}

The present study centred on teachers' emotions that are often insufficiently represented in educational research, even though emotions are an integral part of "school life" (e.g., Jacobs \& Harvey, 2010; Zembylas, 2004). The results of the study indicate that primary school teachers from grades one to five express various pleasant and unpleasant emotions, with unpleasant emotions prevailing. The frequency of teachers' unpleasant emotions was higher than that of pleasant emotions, which fails to achieve the recommended ratio of 3:1 in favour of pleasant emotions (Fredrickson, 2008). The average frequency of teachers' emotion expression decreased from grades one to five. Overall, anger was the most frequently expressed emotion $(N=261)$, followed by joy $(N=$ 151). The intensity of expressed joy and anger was moderate in all five grades, while the assessed suitability of these two emotions was high.

Teachers' anger was aroused mostly in situations when students lacked discipline, were not following instructions or were inattentive. Such triggering situations showed the importance of discipline for teachers and raised the question of teachers' coping strategies in managing discipline in their classroom. The second most frequently expressed emotion, joy, was mostly triggered by situations of students' academic achievement. This may be connected 
to teacher's feeling of responsibility for students' achievement. The teacher is responsible for the quality of teaching but cannot take full responsibility for the students' achievements, even though this line is hard to draw and requires an awareness of teachers' individual beliefs and reflection upon them.

The results of our study have many implications for (future) teachers and for the professionals working with them. In this respect, teacher-oriented education programmes should include different emotion-related content. By encouraging teachers to become aware of the underlying appraisals they give to certain student behaviour through their emotions, we may enhance their emotional understanding and, where necessary, stimulate a change in their "emotional rules" (Chang, 2009; Zembylas, 2004). The process of change is sometimes difficult and may take a long time (Moè et al., 2010). In teacheroriented education programmes, we can promote the development of emotion regulation strategies, especially regarding unpleasant emotions, which may help teachers to improve teaching and learning in their classroom (e.g., Cowie, 2010; Ishak, Iskandar \& Ramli, 2010). The efficient emotion regulation of teachers contributes to better teacher-student relationships, as well as representing a model for students (Bandura, 1997).

The strength of the present study was the application of the observational approach to emotions, providing for an external view of teachers' emotions. The observational approach supplements the more commonly used self-reports (e.g., Hosotani \& Imai-Matsumura, 2011; Zembylas, 2004, 2005). Another advantage of our study was the observation of many different aspects of emotion. Besides this, teachers in our sample came from 93 different schools from various parts of Slovenia. However, the one-person observation of teachers' emotions, leaving more space for the observer's subjectivity, was a weakness of the study. Further research could include a longitudinal approach providing information on the development of teachers' emotions over time. The comparison of teachers' self-perceptions of their emotional process and/or their students' perspective on this matter could also be considered. Further research could also combine the observation and (self)experience of teachers' and students' emotions. 


\section{References}

Bandura, A. (1997). Self-Efficacy: The Exercise of Control. New York: Freeman and Company. Chang, M. L. (2009). Teacher Emotional Management in the Classroom: Appraisals, Regulation, and Coping with Emotions. Paper presented at the 2009 annual meeting of the American Educational Research Association, San Diego, CA.

Cole, P. M., Martin, S. E., \& Dennis, T. A. (2004). Emotion regulation as scientific construct: methodological challenges and directions for child development research. Child Development, 75(2), 317-333.

Cowie, N. (2011). Emotions that experienced English as a foreign language (EFL) teachers feel about their students, their colleagues and their work. Teaching and Teacher Education, 27(1), 29-36.

Day C., \& Leitch, R. (2001). Teachers' and teacher educators' lives: The role of emotion. Teaching and Teacher Education, 17(4), 403-415.

Fredrickson, B. L. (2004). The broaden-and-build theory of positive emotions. Philosophical Transactions of the Royal Society London B: Biological Sciences, 359, 1367-1377.

Fredrickson, B. L. (2005). Positive emotions. In C. R. Snyder, \& S. J. Lopez (Eds.), Handbook of Positive Psychology (pp. 120-134). UK: Oxford University Press.

Fredrickson, B. (2008). Promoting positive affect. In M. Eid, \& R. J. Larsen (Eds.), The science of subjective well-being (pp. 449-468). New York, London: The Guilford Press.

Gordon, T. (1997). Trening večje učinkovitosti za učitelje. Ljubljana: Svetovalni center za otroke, mladostnike in starše.

Grazziano, P. A., Reavis, R. D., Keane, S. P., \& Calkins, S. D. (2007). The role of emotion regulation in children's early academic success. Journal of School Psychology, 45(1), 3-19.

Gross, J. J., \& Thompson, R. A. (2009). Emotion regulation: conceptual foundations. In J. J. Gross (Ed.), Handbook of Emotion Regulation (pp. 3-24). New York, London: The Guilford Press.

Hargreaves, A. (2000). Mixed emotions: teachers' perceptions of their interactions with students. Teaching and Teacher Education, 16(8), 811-826.

Harris, P. (1996). Children and Emotion: The Development of Psychological Understanding. Oxford: Blackwell Publishers.

Hochschild, A. R. (2008). Emotion work, feeling rules, and social structure. In M. Greco, \& P. Stenner (Eds.), Emotions: A Social Science Reader (pp. 121-126). London \& New York: Routledge. Hosotani, R., \& Imai-Matsumura, K. (2011). Emotional experience, expression, and regulation of high-quality Japanese elementary school teachers. Teaching and Teacher Education, 27(6), 1039-1048. Ishak, N. M., Iskandar, I. P., \& Ramli, R. (2010). Emotional intelligence of Malaysian teachers: a comparative study on teachers in daily and residential schools. Procedia - Social and Behavioral Science, 9, 406-412.

Izard, C. E. (1991). The Psychology of Emotion. New York and London: Plenum Press. Jacobs, N., \& Harvey, D. (2010). The extent to which teacher attitudes and expectations predict academic achievement of final year students. Educational Studies, 36(2), 195-206. 
Kelchtermans, G. (2005). Teachers' emotions in educational reforms: Self understanding, vulnerable commitment, and micropolitical literacy. Teaching and Teacher Education, 21(8), 995-1006.

Krevans, J., \& Gibbs, J. C. (1996). Parents' use of inductive discipline: Relation to children's empathy and prosocial behavior. Child Development, 67(6), 3263-3277.

Lamovec, T. (1991). Emocije. Ljubljana: Univerza v Ljubljani - Filozofska fakulteta.

Lazarus, R. S. (1991). Emotion and Adaptation. New York: Oxford University Press.

Meyer, D. K., \& Turner, J. C. (2007). Scaffolding emotions in classroom. In P. A. Schutz, \& R. Pekrun (Eds.), Emotion in Education (pp. 243-258). USA: Elsevier Inc.

Moè, A., Pazzaglia, F., \& Ronconi, L. (2010). When being able is not enough. The combined value of positive affect and self-efficacy for job satisfaction in teaching. Teaching and Teacher Education, 26(5), $1145-1153$.

Oatley, K., \& Jenkins, J. M. (1996). Understanding Emotions. Cambridge, MA: Blackwell Publishers. Papalia, D. E., Wendkos Olds, S., \& Duskin Feldman, R. (2009). A Child's World: Infancy through Adolescence. Boston [etc.]: McGraw-Hill.

Shapiro, S. (2010). Revisiting the teachers' lounge: Reflections on emotional experience and teacher identity. Teaching and Teacher Education, 26(2), 616-621.

Schutz, P. A., Cross, D. I., Hong, J. Y., \& Osborn, J. N. (2007). Teacher identities, beliefs, and goals related to emotions in the classroom. In P. A. Schutz, \& R. Pekrun (Eds.), Emotion in Education (pp. 223-241). USA: Elsevier Inc.

Siegel, D. J. (1999). The Developing Mind. New York, London: The Guilford Press.

Smrtnik Vitulić, H. (2009). The development of understanding of basic emotions from middle childhood to adolescence. Studia Psychologica, 51(1), 3-20.

Sutton, R. E. (2007). Teachers' anger, frustration and self-regulation. In P. A. Schutz, \& R. Pekrun (Eds.), Emotion in Education (pp. 259-274). USA: Elsevier Inc.

Weiner, B. (2007). Examining emotional diversity in the classroom: An attribution theorist considers the moral emotions. In P. A. Schutz, \& R. Pekrun (Eds.), Emotion in Education (pp. 75-88). USA:

Elsevier Inc.

Woolfolk, A. E. (2002). Pedagoška psihologija. Ljubljana: Educy.

Zembylas, M. (2004). The emotional characteristics of teaching: an ethnographic study of one teacher. Teaching and Teacher Education, 20(2), 185-201.

Zembylas, M. (2005). Discursive practices, genealogies and emotional rules: A poststructuralist view on emotion and identity in teaching. Teaching and Teacher Education, 21(8), 935-948. 


\section{Biographical note}

Simona Prosen is Assistant of developmental psychology in the Department of Education Studies at the Faculty of Education in Ljubljana. Her particular fields of research are development in adolescence and the development of attachment. She has encountered and presented the field of emotions and dealing with emotions in her work with various groups - both at the faculty and in healthcare institutions.

Helena Smrtnik Vitulić is Assistant Professor of developmental psychology in the Department of Education Studies at the Faculty of Education in Ljubljana. She specialises in emotions and personal development and published various academic papers in Slovenian and international expert journals.

Olga PolJšak Škraban is Assistant Professor of developmental psychology in the Department of Education Studies at the Faculty of Education in Ljubljana. Her fields of research are the family, development in adolescence and adulthood, and working with parents. She has studied emotions and dealing with emotions within the contexts of family and education. 